\title{
SUSTAINABILITY ANALYSIS OF MANGROVE ECOSYSTEMSIN SUNGAI BELA VILLAGE, INDRAGIRI HILIR REGENCY
}

\section{ANALISIS KEBERLANJUTAN EKOSISTEM MANGROVE DI DESA SUNGAI BELA KABUPATEN INDRAGIRI HILIR}

\author{
Mohd. Riza Fahlifi. SF ${ }^{1}$, Deny Efizon ${ }^{1}$, Adriman ${ }^{1}$. \\ ${ }^{1}$ Kekhususan Ilmu Kelautan Magister Ilmu Kelautan, Pascasarjana Universitas Riau, Pekanbaru, Jl. HR Soe \\ brantas Km 12,5 Simpang Baru, Panam - Pekanbaru, Indonesia 28293 \\ Correspondence Author : Mohd.rizafahlifi@yahoo.com
}

\begin{tabular}{|c|c|}
\hline I NFO A R T I KEL & A B S T R A C T \\
\hline & \multirow[b]{2}{*}{$\begin{array}{l}\text { This study aims to determine the level of sustainability of mangrove ecosystems in } \\
\text { Sungai Bela Village. The method used in this study is a survey method with data } \\
\text { analysis using the Multi Dimensional Scaling (MDS). The results showed that the } \\
\text { index value of the sustainability of mangrove ecosystems showed an ecological } \\
\text { dimension(61.42) with RMS (2.28), social, economic and cultural dimensions } \\
\text { (50.91) with RMS (2.51), legal and institutional dimensions (61.91) with RMS } \\
\text { (1.79).Several factors that affect the sustainability of mangrove ecosystems such } \\
\text { as:(1) mangrove species diversity;(2) density of mangrove ecosystems;(3) content } \\
\text { of sediment organic matter;(4) marketing of fishery products;(5) mangrove } \\
\text { dependence on livelihoods;(6) level of community knowledge;(7) the role of } \\
\text { community leaders; }(8) \text { level of community compliance and (9) community } \\
\text { participation.It can be concluded that the mangrove ecosystem in Sungai Bela } \\
\text { Village with a sufficiently continuous status. }\end{array}$} \\
\hline $\begin{array}{l}\text { Kata kunci: } \\
\text { Sustainability, } \\
\text { Ecosystems, } \\
\text { Mangroves, }\end{array}$ & \\
\hline
\end{tabular}

\section{PENDAHULUAN}

Kabupaten Indragiri Hilir adalah salah satu Kabupaten di Provinsi Riau yang mempunyai ekosistem hutan mangrove dengan wilayah cukup luas. Efizon, (2015) menyatakan bahwa luas ekosistem hutan mangrove di Kabupaten Indragiri Hilir mencapai 129.000 Ha yang terdiri dari jenis mangrove Nypa fruticans, Rhizopora apiculata, Xylocarpus granatum, Avicenia alba, Avicenia Marina dan Bruguiera gymnorhyza.

Desa Sungai Bela merupakan salah satu desa yang memiliki ekosistem mangrove yang cukup luas. Hamparan ekosistem mangrove yang mendominasi mulai dari mangrove sejati sampai dengan mangrove asosisasi. Ekosistem mangrove di Desa Sungai Bela memberikan dampak yang sangat baik bagi kehidupan.

Pegelolaan ekosistem mangrove yang tidak berkelanjutan menjadi ancaman terhadap kondisi hutan mangrove tersebut seperti bahan baku bangunan, kayu arang, lahan perkebunan kelapa sawit dan pemukiman. Pemanfaatan tersebut dapat menyebabkan kerusakan ekosistem, dan lingkungan, seperti terjadinya abrasi, kebakaran hutan, intrusi air laut, penurunan populasi biota - biota yang hidup disekitar mangrove dan hasil tangkapan nelayan. Menurut Yayasan Mitra Insani (2013) bahwa kerusakan hutan mangrove di Desa Sungai Hukum dan Desa Concong disebabkan banyak masyarakat yang memanfaatkan hutan mangrove, terutama Nypa frutican suntuk diambil pucuknya dan dijadikan bahan baku rokok kemudian diekspor ke luar negeri. Kondisi ini diperparah lagi akibat banyaknya masyarakat yang beralih profesi dari 
berkebun dan nelayan menjadi pencari pucuk nipah sehingga menjadi acaman terhadap kelestarian ekosistem mangrove. Informasi mengenai kerusakan ekosistem mangrove yang dijadikan landasan utama peneliti perlunya dilakukan kajian - kajian mengenai analisis keberlanjutan ekosistem mangrove di Desa Sungai Bela Kabupaten Indragiri Hilir Provinsi Riau

\section{METODE PENELITIAN}

Waktu dan Lokasi

Penelitian ini dilaksanakan pada bulan Januari Tahun 2018, lokasi penelitian terletak di Desa Sungai Bela Kabupaten Indragiri Hilir. Penelitian ini dilaksanakan dengan empat tahapan secara sekuensial. Tahapan penelitian dideskripsikan sebagai berikut :

1. Tahap pertama mengidentifikasi indikator - indikator ekosistem hutan mangrove berkelanjutan berdasarkan studi literatur dan pengamatan di lapangan seperti; tingkat kerapatan kerapatan, vegetasi untuk melihat kondisi hutan mangrove di Desa Sungai Bela.

2. Tahapan kedua ; mengidentifikasi kualitas perairan di Desa Sungai Bela seperti ; salinitas, substrat, suhu dan $\mathrm{pH}$.

3. Tahapan ketiga ; menginventarisasi dan menganalisis kondisi ekologi, sosial, ekonomi dan budayaserta hukum dan kelembagaan.

4. Tahapan ke empat ; menganalisis nilai indeks keberlanjutan sistem pengelolaan hutan mangrove dengan Rap - Mforest metode Multidimensional Scaling (MDS) modifikasi dari Rapfish untuk mengetahui sistem hutan pengelolaan hutan mangrove sehingga menghasilkan suatu kebijakan di Desa Sungai Bela.

\section{Metode Pengumpulan Data}

Pada penelitian ini digunakan dua jenis data, yaitu data primer dan data sekunder. Data primer dikumpulkan melalui observasi dan wawancara langsung dilokasi penelitian. Data sekunder dikumpulkan melalui instansi terkait seperti; Dinas Perikanan Kabupaten Indragri Hilir, Dinas Kehutanan Kabupaten Indragiri Hilir, Badan Perencanaan dan Pembangunan Daerah (BAPPEDA), Badan Lingkungan Hidup (KLH), LSM lingkungan hidup, Pemerintah Desa Sungai Bela serta studi penelitian pendahuluan.

\section{Penentuan Kondisi Ekosistem Mangrove}

Penelitian mengenai hutan mangrove di kawasan Desa Sungai Bela dilakukan dengan cara membandingkan setiap stasiun yang ada berdasarkan struktur komunitasnya. Menteri Negara Lingkungan Hidup (2004) menetapkan kriteria baku kerusakan mangrove untuk menentukan status kondisi mangrove yang diklasifikasikan dalam Tabel 1 .

Tabel 1. Kriteria Baku Kerusakan Ekosistem Mangrove

\begin{tabular}{|c|c|c|c|c|}
\hline No. & Kondisi & Kriteria & $\begin{array}{c}\text { Penutupan } \\
(100 \%)\end{array}$ & $\begin{array}{l}\text { Kerapatan } \\
\text { pohon/ ha }\end{array}$ \\
\hline \multirow{2}{*}{1} & \multirow{2}{*}{ Baik } & $\begin{array}{l}\text { Sangat } \\
\text { Padat }\end{array}$ & $\geq 75$ & $\geq 1500$ \\
\hline & & Sedang & $\geq 50<75$ & $\begin{array}{c}\geq 1000< \\
1500\end{array}$ \\
\hline 2 & Rusak & Jarang & $<50$ & $<1000$ \\
\hline
\end{tabular}

Sumber : Menteri Negara Lingkungan Hidup (2004)

Tabel 2. Skor atribut pada setiap dimensi

\begin{tabular}{|c|c|c|c|c|c|}
\hline No & Atribut & $\begin{array}{c}\text { Pilihan } \\
\text { Skor }\end{array}$ & Baik & Buruk & Keterangan \\
\hline $\mathbf{1}$ & Dimensi Ekologi & & & & \\
\hline 1.1 & Kerapatan Mangrove & $0 ; 1 ; 2$ & 2 & 0 & $\begin{array}{l}\rightarrow \text { Jarang } \\
\rightarrow \text { Sedang } \\
\rightarrow \text { Sangat Padat } \\
\text { epmen LH, 2004) }\end{array}$ \\
\hline 1.2 & $\begin{array}{l}\text { Keragaman Jenis } \\
\text { Mangrove }\end{array}$ & $0 ; 1 ; 2$ & 2 & 0 & $\begin{array}{l}(0) \rightarrow \text { Rendah } \\
(1) \rightarrow \text { Sedang } \\
(2) \rightarrow \text { Tinggi }\end{array}$ \\
\hline
\end{tabular}




\begin{tabular}{|c|c|c|c|c|c|}
\hline & & & & & (Kepmen LH, 2004) \\
\hline 1.3 & $\begin{array}{l}\text { Keanekaragaman Jenis } \\
\text { Satwa, Fauna dan Biota } \\
\text { Perairan }\end{array}$ & $0 ; 1 ; 2$ & 2 & 0 & $\begin{array}{l}(0) \rightarrow \text { Rendah } \\
(1) \rightarrow \text { Sedang } \\
(2) \rightarrow \text { Tinggi } \\
(\text { Arifin, 2008) }\end{array}$ \\
\hline 1.4 & $\begin{array}{l}\text { Kondisi Kualitas } \\
\text { Perairan }\end{array}$ & $0 ; 1 ; 2$ & 0 & 2 & $\begin{array}{l}(0) \rightarrow \text { Rendah } \\
(1) \rightarrow \text { Sedang } \\
(2) \rightarrow \text { Tinggi } \\
(\text { Efendi , 2003) }\end{array}$ \\
\hline 1.5 & $\begin{array}{l}\text { Kandungan Bahan } \\
\text { Organik Sedimen }\end{array}$ & $0 ; 1 ; 2$ & 2 & 0 & $\begin{array}{l}) \rightarrow \text { Rendah } \\
\rightarrow \text { sedang } \\
\rightarrow \text { tinggi } \\
(\text { Tech, 1984) }\end{array}$ \\
\hline 1.6 & $\begin{array}{l}\text { Tingkat Ekploitasi } \\
\text { Ekosistem mangrove }\end{array}$ & $0 ; 1 ; 2$ & 2 & 0 & $\begin{array}{l}\rightarrow \text { Tinggi } \\
\rightarrow \text { Sedang } \\
\rightarrow \text { rendah } \\
(\text { Pitcher dan } \\
\text { Preikshot,2001) }\end{array}$ \\
\hline & Tipe Substrat & $0 ; 1 ; 2,3$ & 3 & 0 & $\begin{array}{l}\rightarrow \text { Pasir } \\
\rightarrow \text { Kerikil } \\
\rightarrow \text { Pasir Berlumpur } \\
\rightarrow \text { Lumpur } \\
(\text { Bunchana, 1984) }\end{array}$ \\
\hline 2 & \multicolumn{5}{|c|}{ Dimensi Sosial, Ekonomi dan Budaya } \\
\hline 2.1 & $\begin{array}{l}\text { Ketergantungan pada } \\
\text { mangrove sebagai sumber } \\
\text { nafkah }\end{array}$ & $0 ; 1 ; 2$ & 2 & 0 & $\begin{array}{l}(0) \rightarrow \text { rendah } \\
(1) \rightarrow \text { sedang } \\
(2) \rightarrow \text { tinggi } \\
\text { (Rapfish; Taspamichael dan } \\
\text { Pitcher 2006 ) }\end{array}$ \\
\hline 2.2 & $\begin{array}{l}\text { Tingkat Pendapatan } \\
\text { Masyarakat }\end{array}$ & $0 ; 1 ; 2$ & 2 & 0 & $\begin{array}{l}(0) \rightarrow \text { Rendah } \\
(1) \rightarrow \text { Sedang } \\
(2) \text { Tinggi } \\
\text { (Rapfish; Taspamichael dan } \\
\text { Pitcher } 2006 \text { ) }\end{array}$ \\
\hline 2.3 & Pemasarahan Hasil Perikanan & $0 ; 1 ; 2 ; 3$ & 3 & 0 & $\begin{array}{l}(0) \rightarrow \text { Pasar Daerah } \\
(1) \rightarrow \text { Pasar Lokal } \\
(2) \rightarrow \text { Pasar Nasional } \\
(3) \rightarrow \text { Pasar Internasional } \\
(\text { Yofi, 2016) }\end{array}$ \\
\hline 2.4 & $\begin{array}{l}\text { Tingkat Kesejahteraan } \\
\text { Masyarakat Pesisir }\end{array}$ & $0 ; 1 ; 2$ & 2 & 0 & $\begin{array}{l}(0) \rightarrow \text { rendah }(<10 \%) \\
(1) \rightarrow \text { sedang }(10-20 \%) \\
(2) \rightarrow \text { tinggi }(>20 \%) \\
(\text { Pitcher dan } \\
\text { Preikshot,2001) }\end{array}$ \\
\hline 2.5 & Tingkat Pendidikan & $0 ; 1 ; 2 ; 3$ & 3 & 0 & $\begin{array}{l}(0) \rightarrow \text { Tidak Tamat SD } \\
(1) \rightarrow \text { Tamat SD - SMP } \\
(2) \rightarrow \text { Tamat SMA } \\
(3) \rightarrow \text { Tamat D3 -S1 } \\
(\text { Pitcher dan } \\
\text { Preikshot,2001) }\end{array}$ \\
\hline 2.6 & Pengetahuan lingkungan & $0 ; 1 ; 2$ & 2 & 0 & $\begin{array}{l}(0) \rightarrow \text { Rendah } \\
(1) \rightarrow \text { Sedang } \\
(2) \rightarrow \text { Tinggi } \\
(\text { Pitcher dan } \\
\text { Preikshot,2001) }\end{array}$ \\
\hline 2.7 & Pola hubangan stakeholder & $0 ; 1 ; 2$ & 2 & 0 & $\begin{array}{l}(0) \rightarrow \text { rendah } \\
(1) \rightarrow \text { sedang } \\
(2) \rightarrow \text { tinggi } \\
(\text { Pitcher dan Preikshot, } \\
2001)\end{array}$ \\
\hline 2.8 & Potensi konflik pemanfaatan & $0 ; 1$ & 1 & 0 & $(0) \rightarrow$ ada \\
\hline
\end{tabular}




\begin{tabular}{|c|c|c|c|c|c|c|c|}
\hline & lahan & & & & \multicolumn{3}{|c|}{$\begin{array}{l}(1) \rightarrow \text { Tidak ada } \\
\text { (Rapfish; Taspamichael dan } \\
\text { Pitcher 2006 ) }\end{array}$} \\
\hline 2.9 & Nilai Estetika & $0 ; 1 ; 2$ & 2 & 0 & \multicolumn{3}{|c|}{$\begin{array}{l}(0) \rightarrow \text { Rendah } \\
(1) \rightarrow \text { Sedang } \\
(2) \rightarrow \text { Tinggi } \\
(\text { Arifin, 2008) }\end{array}$} \\
\hline 3 & \multicolumn{7}{|c|}{ Dimensi hukum/kelembagaan } \\
\hline 3.1 & $\begin{array}{l}\text { Ketersediaan Lembaga } \\
\text { Formal }\end{array}$ & $0 ; 1$ & 1 & 0 & \multicolumn{3}{|c|}{$\begin{array}{l}(0) \rightarrow \text { Tidak Ada } \\
(1) \rightarrow \text { Ada } \\
(\text { Arifin, 2008) }\end{array}$} \\
\hline 3.2 & $\begin{array}{l}\text { Ketersedian Lembaga } \\
\text { Infromal }\end{array}$ & $0 ; 1$ & 1 & 0 & \multicolumn{3}{|c|}{$\begin{array}{l}(0) \rightarrow \text { Tidak Ada } \\
(1) \rightarrow \text { Ada } \\
(\text { Arifin, 2008) }\end{array}$} \\
\hline 3.3 & $\begin{array}{l}\text { Ketersedian Peraturan } \\
\text { Formal }\end{array}$ & $0 ; 1$ & 1 & 0 & \multicolumn{3}{|c|}{$\begin{array}{l}(0) \rightarrow \text { Tidak Ada } \\
(1) \rightarrow \text { Ada } \\
(\text { Arifin, 2008) }\end{array}$} \\
\hline 3.4 & $\begin{array}{l}\text { Ketersedian peraturan } \\
\text { informal }\end{array}$ & $0 ; 1$ & 1 & 0 & \multicolumn{3}{|c|}{$\begin{array}{l}(0) \rightarrow \text { Tidak Ada } \\
(1) \rightarrow \text { Ada } \\
(\text { Arifin, 2008) }\end{array}$} \\
\hline 3.5 & $\begin{array}{l}\text { Tingkat kepatuhan } \\
\text { masyarakat }\end{array}$ & $0 ; 1 ; 2$ & 2 & 0 & \multicolumn{3}{|c|}{$\begin{array}{l}(0) \rightarrow \text { tidak patuh } \\
(1) \rightarrow \text { sedang } \\
(2) \rightarrow \text { patuh } \\
(\text { Nikijuluw, 2002) }\end{array}$} \\
\hline 3.6 & $\begin{array}{l}\text { Peran Tokoh } \\
\text { Masyarakat Desa } \\
\text { Sungai Bela }\end{array}$ & $0 ; 1 ; 2$ & 2 & 0 & \multicolumn{3}{|c|}{$\begin{array}{l}(0) \rightarrow \text { tidak ada } \\
(1) \rightarrow \text { Sedikit } \\
(2) \rightarrow \text { Cukup } \\
((\text { Nikijuluw, 2002) }\end{array}$} \\
\hline 3.7 & $\begin{array}{l}\text { Penyuluhan } \\
\text { Hukum dan } \\
\text { Lingkungan }\end{array}$ & $0 ; 1 ; 2$ & 2 & 0 & \multicolumn{3}{|c|}{$\begin{array}{l}(0) \rightarrow \text { tidak pernah } \\
(1) \rightarrow \text { jarang } \\
(2) \rightarrow \text { sering } \\
(\text { Nikijuluw, 2002) }\end{array}$} \\
\hline 3.8 & $\begin{array}{l}\text { Partisipasi } \\
\text { Masyarakat }\end{array}$ & $0 ; 1 ; 2$ & 2 & 0 & \multicolumn{3}{|c|}{$\begin{array}{l}(0) \rightarrow \text { Rendah } \\
(1) \rightarrow \text { Sedang } \\
(2) \rightarrow \text { Tinggi } \\
(\text { Nikijuluw, 2002) }\end{array}$} \\
\hline 3.9 & $\begin{array}{l}\text { Pelaksanaan } \\
\text { Pemantauan, } \\
\text { Pengawasan }\end{array}$ & $0,1,2$ & 2 & 0 & \multicolumn{3}{|c|}{$\begin{array}{l}(0) \rightarrow \text { Rendah } \\
(1) \rightarrow \text { Sedang } \\
(2) \rightarrow \text { Tinggi } \\
(\text { Nikijuluw, 2002) }\end{array}$} \\
\hline \multicolumn{3}{|c|}{ HASIL DAN PEMBAHASAN } & Meliacea & & Xylocarpus & $\begin{array}{l}\text { B. } \\
\text { parviflora } \\
\text { Xylocarpus } \\
\text { granatum }\end{array}$ & $\begin{array}{l}\text { Lenggadai } \\
\text { Nyiri }\end{array}$ \\
\hline \multirow{2}{*}{\multicolumn{3}{|c|}{$\begin{array}{l}\text { Vegetasi Mangrove } \\
\text { Hasil pengamatan vegetasi mangrove } \\
\text { yang tersebar pada ketiga stasiun penelitian }\end{array}$}} & Arecaceae & & Nypa & $\begin{array}{l}\text { Nypa } \\
\text { fruticans }\end{array}$ & Nipah \\
\hline & & & Pteridaceae & & Acrostichum & $\begin{array}{l}\text { Acrostichum } \\
\text { aureum }\end{array}$ & Piai \\
\hline
\end{tabular}

di Desa Sungai Bela dapat ditemukan 7 spesies jenis mangrove. Untuk lebih jelasnya jenis vegetetasi mangrove yang teridentifikasi dapat dilihat pada Tabel 3 berikut.

Tabel 3. Jenis Vegetasi Mangrove yang terdapat di Desa Sungai Bela

\begin{tabular}{|c|c|c|c|}
\hline Family & Genus & Spesies & $\begin{array}{c}\text { Nama } \\
\text { Daerah }\end{array}$ \\
\hline \multirow[t]{2}{*}{ Rhizophoraceae } & Rhizophora & $\begin{array}{l}\text { Rhizophora } \\
\text { apiculata } \\
R . \\
\text { mucronata }\end{array}$ & $\begin{array}{l}\text { Bakau } \\
\text { putih } \\
\text { Bakau } \\
\text { dayak }\end{array}$ \\
\hline & Bruguiera & $\begin{array}{l}\text { Bruguiera } \\
\text { gymnorrhiza }\end{array}$ & Tumu \\
\hline
\end{tabular}

Sumber : Data Primer, 2018

Berdasarkan hasil dari pengamatan vegetasi mangrove yang telah dilakukan di kawasan Desa Sungai Bela, komposisi pada setiap stasiun memiliki jenis yang sama dan tipe pertumbuhan yang hampir sama. Dahuri, (2003) juga mendapatkan jenis yang hampir sama di pesisir Tanjung Sekodi Kabupaten Bengkalis merupakan vegetasi mangrove yang menyusun wilayah Tanjung Sekodi Kabupaten Bengkalis.

Kerapatan Jenis Mangrove 
Kerapatan ekosistem mangrove di Desa Sungai Bela Kecamatan Kuala Indragiri secara umum dapat digambarkan katagori dalam kerapatan yang baik dengan nilai sedang. Nilai rata - rata kerapatan ekosistem mangrove yang diamati berdasarkan dari ketiga titik stasiun adalah 1162.63 Ha. Untuk lebih jelasnya nilai kerapatan ekosistem mangrove pada ketiga stasiun dapat dilihat pada Tabel 4.

Tabel 4. Kerapatan Jenis Mangrove Pada Setiap Stasiun

\begin{tabular}{|c|c|c|c|c|c|c|}
\hline \multirow[b]{2}{*}{ Nama Spesies } & \multicolumn{2}{|c|}{ STASIUN 1} & \multicolumn{2}{|c|}{ STASIUN 2} & \multicolumn{2}{|c|}{ STASIUN 3} \\
\hline & $\begin{array}{c}\text { Jmlh } \\
\text { Dijumpai }\end{array}$ & $\begin{array}{l}\text { Kerapatan } \\
\text { (Pohon/ha) }\end{array}$ & $\begin{array}{c}\text { Jmlh } \\
\text { dijumpai }\end{array}$ & $\begin{array}{l}\text { Kerapatan } \\
\text { (Pohon/ha) }\end{array}$ & $\begin{array}{c}\text { Jmlh } \\
\text { Dijumpai }\end{array}$ & $\begin{array}{l}\text { Kerapatan } \\
\text { (Pohon/ha) }\end{array}$ \\
\hline$X$. granatum & 25 & 277,78 & 24 & 266,67 & 50 & 555,56 \\
\hline R. apiculata & 60 & 666,67 & 50 & 555,56 & 30 & 333,33 \\
\hline R. mucronata & 2 & 22,22 & 3 & 33,33 & 4 & 44,44 \\
\hline B. gymnorhiza & 2 & 22,22 & 15 & 166,67 & 4 & 44,44 \\
\hline B. parviflora & 0 & 0 & 0 & 0 & 2 & 22,22 \\
\hline Nypa Fruticans & 12 & 133,33 & 5 & 55,56 & 5 & 55,56 \\
\hline $\begin{array}{l}\text { Acrosthicum } \\
\text { aureum }\end{array}$ & 5 & 55,56 & 7 & 77,78 & 9 & 100,00 \\
\hline Jumlah & 106 & 1177,78 & 104 & 1155,56 & 104 & 1155,56 \\
\hline
\end{tabular}

Sumber : Data Primer, 2018

Kondisi hutan mangrove di Desa Sungai Bela dengan nilai rata - rata 1162.63 pohon/ha tergolong dalam kriteria kerapatan sedang dengan kondisi yang baik sesuai keputusan Menteri Lingkungan Hidup (2004) yang menetapkan tentang kriteria baku mengenai kerusakan hutan mangrove dimana kerapatan pohon $\geq 1000$ $<1500$ termasuk dalam kriteria kerapatan sedang dengan kondisi hutan masih baik. Randi (2011), bahwa kondisi hutan mangrove pada muara Sungai Dumai termasuk dalam kriteria kerapatan sangat baik dengan kondisi hutan masih baik dengan rata - rata kerapatan 1556 pohon/ha.

\section{Kondisi Kualitas perairan}

Pengukuran kualitas perairan di Desa Sungai Bela dilakukan pada saat pasang dengan parameter yang diukur dalam penelitian ini yaitu salinitas, kecerahan, suhu, $\mathrm{pH}$ perairan, $\mathrm{pH}$ sedimen. Rata - rata hasil pengukuran parameter kualitas air dapat dilihat pada Tabel 6 .

Tabel 6. Nilai Pengukuran Kualita Perairan di Kawasan Sungai Bela

\begin{tabular}{|c|c|c|c|}
\hline $\begin{array}{l}\text { Parameter } \\
\text { Kualitas Perairan }\end{array}$ & $\begin{array}{l}\text { Stasiun } \\
\text { I }\end{array}$ & $\begin{array}{l}\text { Stasiun } \\
\text { II }\end{array}$ & $\begin{array}{l}\text { Stasiun } \\
\text { III }\end{array}$ \\
\hline Salinitas (\%o) & 17 & 15 & 16 \\
\hline Kecerahan $(\mathrm{cm})$ & 58 & 47 & 60 \\
\hline Suhu $\left({ }^{\circ} \mathrm{C}\right)$ & 29 & 28 & 29 \\
\hline $\mathrm{pH}$ Air & 7 & 6 & 7 \\
\hline
\end{tabular}

Sumber : Data Primer 2018

Berdasarkan Tabel 21, salinitas di perairan Desa Sungai Bela berkisar antara 15 - 17 ppt. Nurhayati (2002), mengemukakan bahwa keberadaan nilai salinitas dalam distribusinya sangat dipengaruhi oleh beberapa faktor antara lain adanya interaksi masuknya air tawar melalui sungai, juga dipengaruhi penguapan dan curah hujan. Bengen (2004) dalam Ahmadryadi (2017), menyatakan bahwa salah satu karakteristik habitat hutan mangrove adalah airnya bersalinitas payau $(2-22 \%)$ hingga asin (38\%).

Suhu perairan berkisar antara $28^{\circ} \mathrm{C}$ - $29^{\circ} \mathrm{C}$ Kolehmainen et al (1974) dalam Ahmadryadi (2018) menyatakan, suhu yang baik untuk mangrove tidak kurang dari 20 ${ }^{\circ} \mathrm{C}$ dan Kementerian Lingkungan Hidup (2004) menyatakan suhu optimal bagi mangrove adalah $28-32^{\circ} \mathrm{C}$. Pengukuran derajat keasaman $(\mathrm{pH})$ di perairan Desa Sungai Bela memiliki rata-rata $6-7$, kisaran angka ini sangat bagus sekali untuk pertembuhan ekosistem mangrove. Simanjuntak (2009), mengungkapkan pH perairan merupakan parameter cukup penting dalam memantau kestabilan suatu perairan.

Kecerahan perairan di Desa Sungai Bela berisar antara $47-60 \%$ hal ini, disebabkan karena perairan Desa Sungai Bela memiliki tipe substrat berlumpur. Berdasarkan hasil pengamatan di lapangan parameter kualitas perairan di Desa Sungai Bela masih tergolong baik, karena masih diambang batas baku mutu.

\section{Kandungan Bahan Organik Sedimen}

Kandungan bahan organik sedimen pada ketiga stasiun pengamatan berkisar antara 24,42 - 30, $77 \%$. Persentase kandungan bahan organik dapat dilihat pada Tabel 7.

Tabel 7. Persentase Kandungan Bahan Organik Sedimen di Desa Sungai Bela.

\begin{tabular}{cc}
\hline $\begin{array}{c}\text { Stasiun } \\
\text { Penelitian }\end{array}$ & $\begin{array}{c}\text { Kandungan } \\
\text { Bahan Organik } \\
(\boldsymbol{\%})\end{array}$ \\
\hline I & 30,77 \\
II & 24,42 \\
III & 26,47 \\
\hline
\end{tabular}

Sumber : Data Primer, 2018

Bahan organik yang terkandung di perairan Sungai Bela cenderung seragam berkisar antara 24,42 - 30,77 \% hal ini dikarenakan substrat pada setiap stasiun dominan berlumpur. Rifardi (2008), menyatakan bahwa sedimen yang berlumpur cenderung lebih banyak mengandung bahan organik dibanding sedimen berparsir.

Analisis Keberlanjutan

Dimensi Ekologi 
Hasil analisis MDS yang menggunakan Rap-MP forest menunjukan nilai keberlanjutan pada dimensi ekologi sebesar $61,42 \%$ (cukup berlanjut) (Gambar 1). Indikator kunci yang diperkirakan paling berpengaruh terhadap keberlanjutan dimensi ekologi sebanyak 3 indikator yaitu ; (1) keanekaragaman jenis mangrove 5.58 $\%$, (2) kerapatan ekosistem mangrove 4,93 $\%$ dan kandungan bahan organik sedimen $4,99 \%$. (Gambar 2).

Penetapan status keberlanjutan sesuai dengan pernyataan Susilo (2003) dalam Suaseh (2017), menyatakan bahwa nilai skor dengan rentang nilai 50,01 75,00 berdasarkan klasifikasi kondisi atau status keberlanjutan ditunjukkan dengan status cukup berlanjut.

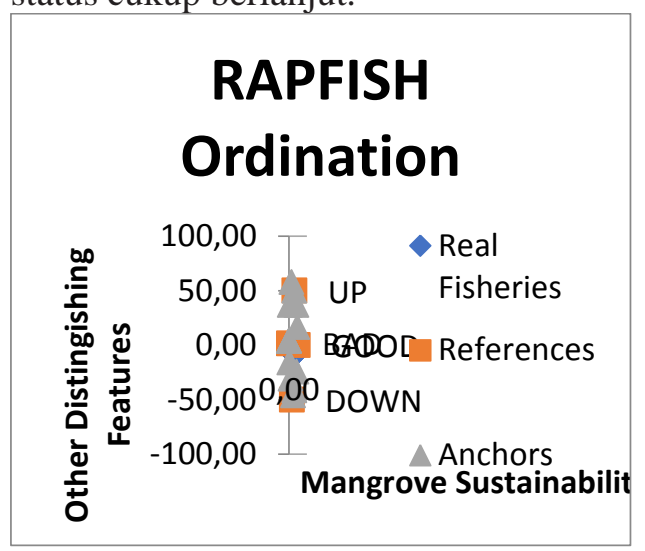

Dimensi Sosial, Ekonomi dan Budaya

Hasil analisis MDS yang menggunakan Rap-MP forest menunjukan nilai keberlanjutan pada dimensi sosial, ekonomi dan budaya sebesar 50,9 \% (cukup berlanjut) (Gambar 3). Indikator kunci yang diperkirakan paling berpengaruh terhadap keberlanjutan dimensi ekologi sebanyak 3 indikator yaitu ; (1) pemasaran hasil perikanan $2.47 \%$, (2) ketergantungan pada ekosistem mangrove sebagai sumber nafkah $2,24 \%$ dan tingkat pengetahuan $2,10 \%$. (Gambar 4).
Gambar 1. Status Keberlanjutan pada Dimensi Ekologi

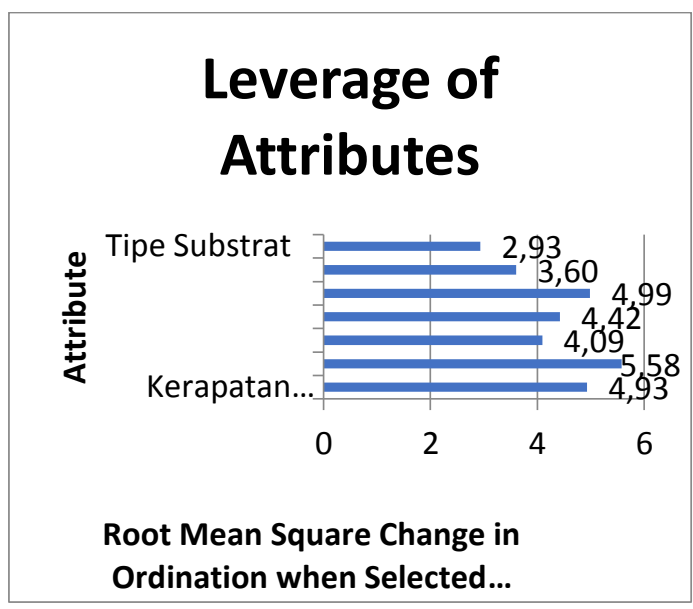

Gambar 2. Faktor - Faktor yang Berpengaruh pada Dimensi Ekologi

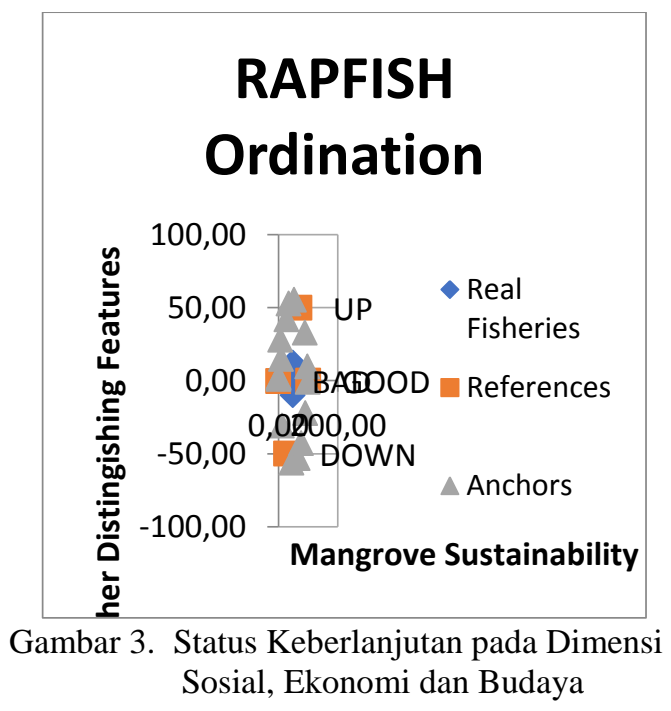




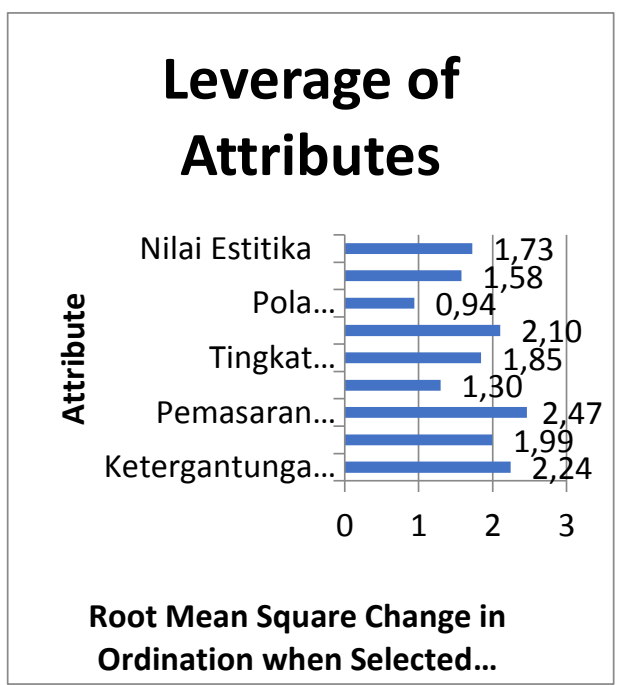

Gambar 4. Faktor - Faktor yang

Berpengaruh pada Dimensi

Sosial, Ekonomi dan Budaya

Dimensi Hukum dan Kelembagaan

Penentuan skor pada dimensi hukum dan kelembagaan untuk menetapkan status keberlanjutan ekosistem mangrove di Desa Sungai Bela diperoleh dari data dari hasil wawancara terhadap responden yang telah ditentukan meliputi data ketersedian lembaga formal, ketersedian lembaga informal, ketersedian peraturan formal, ketersedian peraturan informal, tingkat kepatuhan masyarakat, peran tokoh masyarakat, penyuluhan hukum dan lingkungan, partisipasi masyarakat, pelaksaan, pemantauan dan pengawasan. Hasil analisis MDS yang menggunakan Rap-MP forest menunjukan nilai keberlanjutan pada dimensi hukum dan kelembagaan sebesar 61,9 \% (cukup berlanjut) (Gambar 5). Indikator kunci yang diperkirakan paling berpengaruh terhadap keberlanjutan dimensi ekologi sebanyak 3 indikator yaitu ; (1) peran tokoh masyarakat $6,26 \%$, (2) tingkat kepatuhan masyarakat $3,96 \%$ dan tingkat apresiasi masyarakat $3,69 \%$. (Gambar 6).

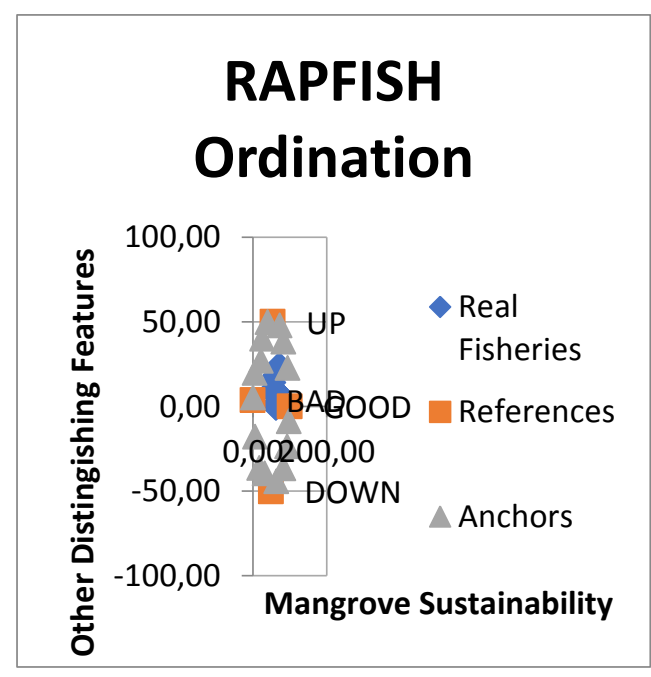

Gambar 5. Status Keberlanjutan pada

Dimensi Hukum dan

Kelembagaan

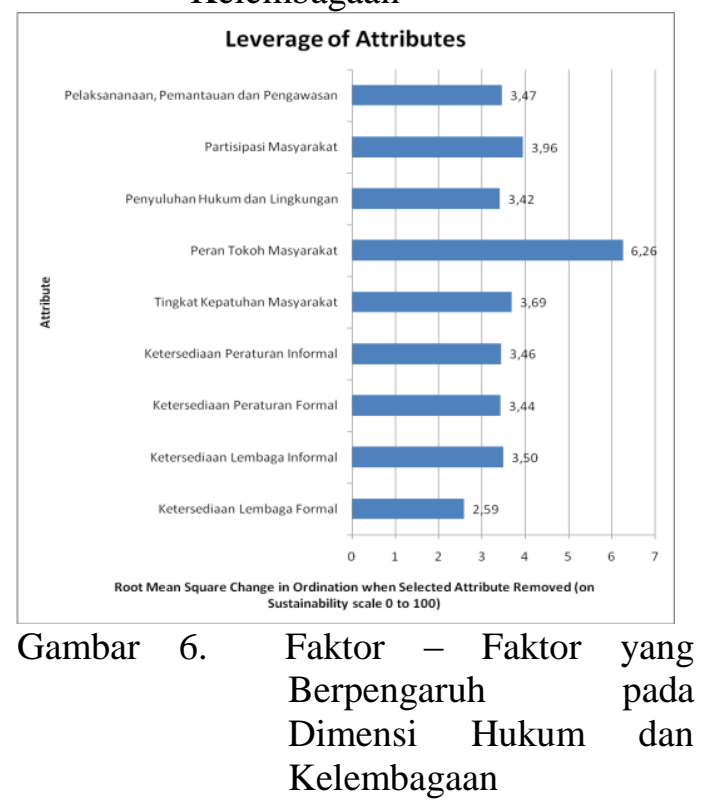

Nilai Indeks dan Status Keberlanjutan

Status keberlanjutan Ekosistem mangrove digambarkan melalui 25 atribut. Seluruh atribut ini terdiri atas 8 atribut dalam dimensi ekologi, dimensi sosial, ekonomi dan budaya dan dimensi hukum dan kelembagaan dengan masing - masing nilai indeks ekologi (61,42), sosial, ekonomi dan budaya $(50,91)$, hukum dan kelembagaan $(61,92)$ Nilai indeks dan status keberlanjutan ketiga dimensi ekosistem mangrove di Desa Sungai Bela dalam bentuk diagram layang (kite diagram) yang ditunjukan pada Gambar 7. 


\section{Gambar 7. Diagram Layang Ekosistem Mangrove}

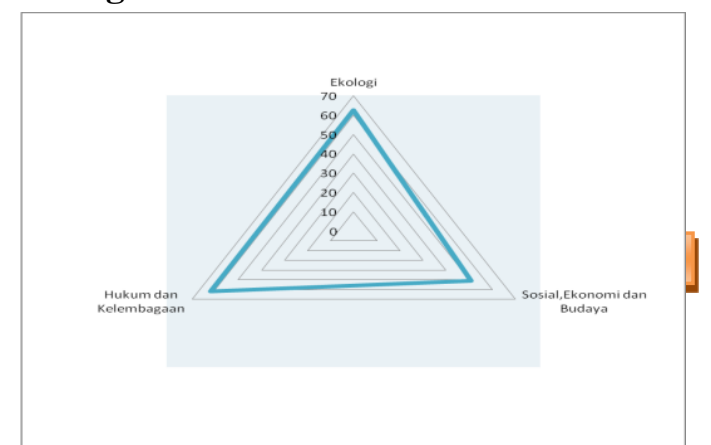

Sumber : Hasil Analisis Data, 2018

Strategi dan Arah rekomendasi

Keberlanjutan Eksositem Mangrove di

Desa Sungai Bela

Penyusunan strategi keberlanjutan ekosistem mangrove di Desa Sungai Bela dilakukan dengan melihat interaksi antara komponen komponen ekologi, ekonomi, sosial dan budaya, serta hukum dan kelembagaan. Untuk mempermudah pembuatan kebijakan yang dapat mendorong pengembangan pengelolaan ekosistem mangrove di Desa Sungai Bela yang berkelanjutan, maka diperlukan strategi keberlanjutan. Strategi yang dilakukan adalah dengan membuat target capain kinerja dalam bentuk kebijakan operasional (implementasi) yang dapat dilakukan dalam jangka waktu tertentu. Adapun strategi yang dilakukan adalah dengan intervensi dan perbaikan dalam upaya meningkatkan nilai skala pada atribut-atribut yang memiliki pengaruh besar terhadap keberlanjutan ekosistem mangrove dapat dilihat pada Tabel 8 berikut.

Tabel 8. Perubahan kenaikan skala pada setiap dimensi dalam strategi pengelolaan ekosistem mangrove di Desa Sungai Bela

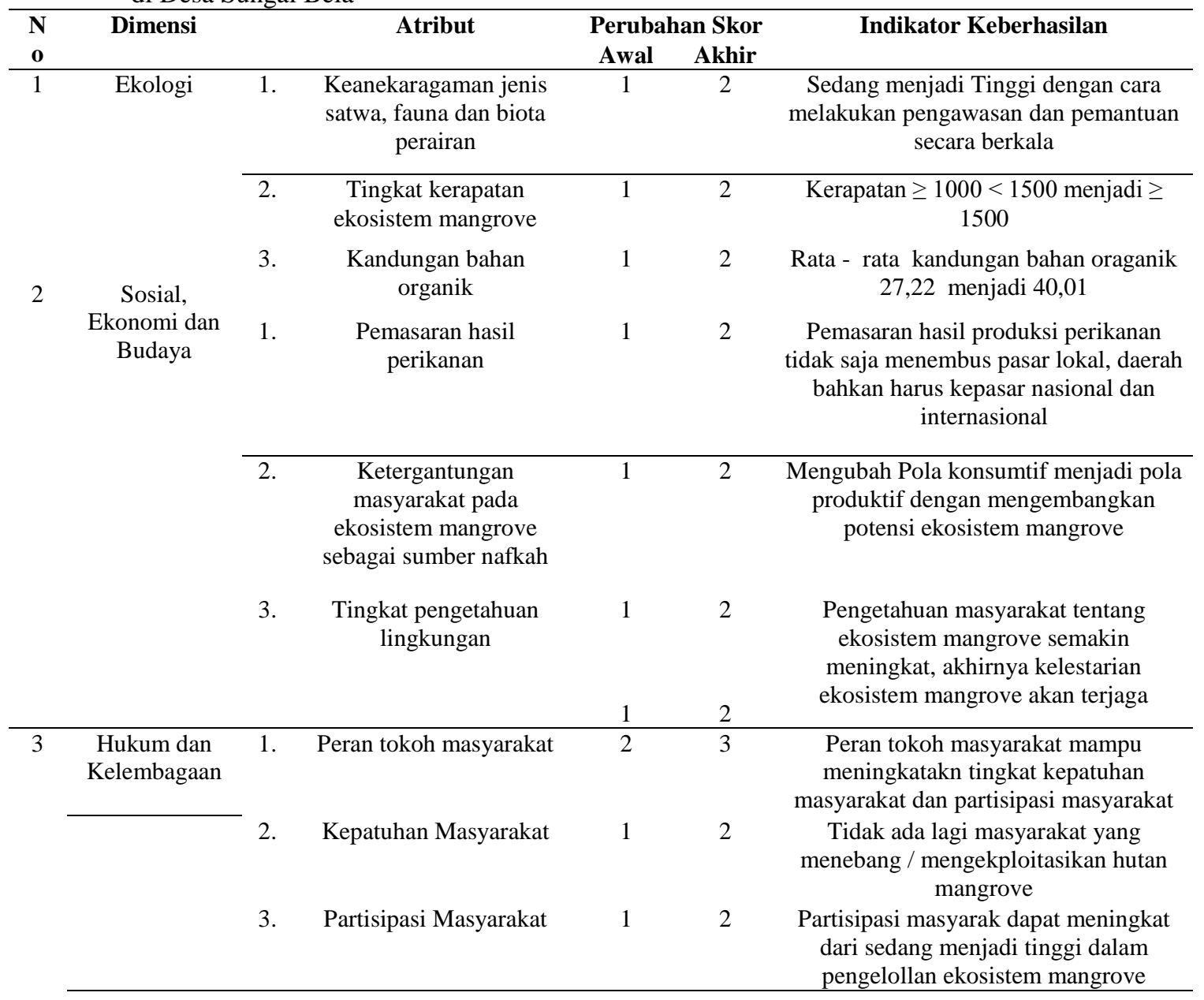

\section{KESIMPULAN}

Kondisi ekosistem mangrove di Desa Sungai Bela dalam katagori tergolong cukup baik, kisaran rata - rata kerapatan mangrove berkisar antara 1177,78 pohon/ha 1155,56 pohon/ha. Status keberlanjutan ekosistem mangrove di Desa Sungai Bela pada 
dimensi ekologi, sosial, ekonomi dan budaya serta hukum dan kelembagaan pada saat ini secara multidimensi termasuk dalam kategori cukup berlanjut dengan nilai rata - rata indeks keberlanjanjutan 58,41. Sedangkan strategi atau rekomendasi yang dapat dilakukan untuk meningkatkan nilai keberlanjutan adalah peningkatan koordinasi antar stakeholders. Selain itu, program penyuluhan, pelatihan dan pembinaan dibidang kelestarian ekosistem mangrove dan bidang perikanan menjadi faktor utama yang menjadi perhatian pihak terkait untuk dilaksanakan secara berkelanjutan di Desa Sungai Bela.

\section{SARAN}

1. Perlu dilakukan penguatan penegakan peraturan daerah terhadap eksploitasi ekosistem mangrove di desa Sungai Bela, konservasi atau reboisasi secara berkala dilakukan oleh pemerintah daerah melalaui Peraturan Dearah atau Peraturan Desa.

2. Peningkatan UMKM dibidang pengelolaan hasil perikanan dan ekosistem mangrove dengan cara mengaktifkan KOPERASI nelayan atau melakukan pembentukan KOPERASI/BUMDES guna menjadi solusi bagi masyarakat pesisir Desa Sungai Bela untuk meningkatkan kesejahteraannya.

Memperbanyak kelompok pengawas dibidangn konservasi dan perikanan di Desa Sungai Bela maupun seluruh desa pesisir yang berada di Kabupaten Indragiri Hilir untuk menegakan undang - undang, peraturan daerah dan peraturan desa.

\section{DAFTAR PUSTAKA}

Adriman. 2012. Desain Pengelolaan Ekosistem Terumbu Karang secara Berkelanjutan di Kawasan Konservasi Laut Daerah Bintan Timur Kepulauan Riau. Disertasi, Bogor. Sekolah Pascasarjana, Institut Pertanian Bogor.

A. Randi, 2011. Kerapatan Pohon Mangrove dan Kelimpahan Makrozoobenthos di Muara Sungai Dumia. Skripsi Universitas Riau. Tidak diterbitkan

Bengen, D.G. 2004. Pedoman Teknis: Pengenalan dan Pengelolaan Ekosistem Mangrove.PKSPL-IPB. Bogor (ID): IPB Pr.

Efizon, D., M. Fauzi., Rosliadi., A.H. Yani dan R. Junaidi. 2017. Pencadangan Kawasan Konservasi Perairan Pesisir dan Pulau-Pulau Kecil di Kabupaten Indragiri Hilir Provinsi Riau. Prosiding Seminar Antarbangsa ke-10 Malaka, Malaysia.18-19 November 2017.

Kementerian Negara Lingkungan Hidup, 2004. Keputusan Menteri Negara Lingkungan Hidup Nomor 201 Tahun 2004. Tentang Kriteria Baku dan Pedoman Penentuan Kerusakan Mangrove.

Nurhayati. 2002. Karakteristik Hidrografi dan Arus di Perairan Selat Malaka, Perairan Indonesia Oseanografi.Biologi dan Lingkungan. Puslit Oseanografi LIPI. Jakarta ; 1-8.

Ramdani D., E. Liviawaty dan Y. N. Ihsan. 2015. Pengaruh Perbedaan Struktur Komunitas Mangrove Terhadap Konsentrasi N dan P di Perairan Hutan Sancang Garut. Perikan dan Kelautan. 6(2):7-14.

Rifardi. 2008. Deposisi Sedimen di Perairan Laut Dangkal. Jurnal Ilmu Kelautan Universitas Diponegoro.

Santoso, N. dan Arifin, 1998. Rehabilitas Hutan Mangrove Pada Jalur Hijau Di Indonesia.Lembaga Pengkajian dan Pengembangan Mangrove (LPP Mangrove). Jakarta, Indonesia.

Email:

rizapahlevi@gmail.com

deni_yasmin@yahoo.co.id

adry04pku@yahoo.com 